\title{
The effect of magnetic field on copper in various corrosive medium
}

\begin{abstract}
The effect of applied magnetic field on the corrosion behaviour of copper within various corrosive medium is investigated. The copper coupon is immersed in $0.5 \mathrm{M} \mathrm{HCl}, 0.5 \mathrm{M} \mathrm{NaCl}$ and $0.5 \mathrm{M} \mathrm{NaOH}$ with or without applying up to $40 \mathrm{mT}$ magnetic fields for 24 hours. The weight loss of copper coupon in $\mathrm{HCl}$ increased up to $96.56 \%$ with applied magnetic fields. However, in $\mathrm{NaOH}$ medium, only $33.33 \%$ more weight loss was observed and no difference were observed for coupons in $\mathrm{NaCl}$ when magnetic field is applied. This observation indicates that corrosion behaviour in $\mathrm{HCl}$ and $\mathrm{NaOH}$ is controlled by mass transport that can be influenced by the induced magneto hydrodynamics effect when magnetic field is applied. There was no change in weight loss of copper in $\mathrm{NaCl}$ when magnetic field is applied because the corrosion mechanism of copper in $\mathrm{NaCl}$ is governed by electron charge transfer.
\end{abstract}

Keyword: Corrosion; Magnetic field; Copper 